\title{
Marketing in Technology-Intensive Markets: Toward a Conceptual Framework
}

Markets in which technology assumes a central role are becoming driving forces of the economy. The authors label these "technology-intensive" (TI) markets. Despite their importance, however, there is not a clear understanding of the features of a TI market. Using scientific know-how as the foundational concept, the authors explore the nuances of know-how creation, dissemination, and use to identify eight features of TI markets. With a series of reputable empirical propositions, they also study four marketing decisions, beginning with the most fundamental, that is, the vertical positioning decision (the firm's decision about what it sells). Product design decisions (both platform and modularity), transfer rights decisions (incorporating both price formats and licensing restrictions), and migration decisions (whether and how to move customers through an ongoing stream of technological innovations) round out the set.

$\mathbf{T}$ echnology is at the core of diverse contemporary markets, ranging from commonplace business and consumer products (e.g., fax machines, digital "pets") to esoteric products with diverse yet fundamental applications (e.g., routers, extensible object-oriented databases, digital signal processors, gene sequence analyzers). We call these "technology-intensive" (TI) markets. Such markets are significant in several respects.

Technology is a powerful engine of economic progress. It has been estimated that TI markets added almost a full point to U.S. economic growth in 1998 (Mandel 1998). This is no transitory phenomenon, either. Technology has been the principal driver of the astounding increases in productivity and well-being of societies achieved since the Industrial Revolution (e.g., Mokyr 1990). Furthermore, these trends show no sign of abating. To the contrary, the effects and influence of technology are expected to accelerate (Quinn 1992). These markets are growing at twice the growth rate of the economy, according to government statistics (Technology in the National Interest 1996).

However, consensus views of the business implications of these markets are lacking. Technology evangelists assert that these markets are as "different as the moon is from the earth" (Dyson 1995). Even some accounts in the marketing literature accord a limited role for marketing in TI settings (e.g., Workman 1993). However, skeptics contend that nothing is fundamentally different about such markets, and conventional marketing insights into branding, positioning, distribution, and so forth can be extrapolated usefully to $\mathrm{TI}$ markets.

George John is Research Professor, Marketing Department, Carlson School of Management, University of Minnesota. Allen Weiss is Associate Professor and David and Jeanne Tappen Fellow of Marketing, and Shantanu Dutta is Associate Prolessor of Marketing, Marshall School of Business, University of Southern California.
Although work in marketing and allied fields has improved considerably our understanding of TI domains (e.g., Capon and Glazer 1987) and large numbers of analytic models have been developed for particular topics such as compatibility and network externalities, empirical evidence is scarce. Thus, it is difficult to sort through these competing views about the nature of marketing decisions in these markets. In short, our current understanding of TI markets is sparse, disparate, and without consensus.

These disagreements carry over into the public policy and antitrust arena. The argument is often made that the dynamic business aspects of technology-driven markets render conventional business and strategy analysis useless. However, consider the contrasting view offered by a deputy assistant attorney general: "rapid technological progress hardly implies that antitrust enforcers should sit on the sidelines ... our job is to ensure that incumbent firms do not use their power to block technological progress" (Shapiro 1996).

Our goal is to offer a framework that can motivate empirical research. Scientific know-how is the foundational element of our framework. The sheer intensity of scientific know-how in TI markets endows them with a set of characteristic features. We identify four marketing issues that become salient in these circumstances: vertical positioning decisions, which represent the firm's decision of what it sells; platform positioning decisions; transfer rights decisions; and migration decisions over overlapping generations of technological innovations. We articulate linkages between the features and these marketing decisions as a series of testable propositions that researchers might find useful in conducting empirical work.

\section{Know-How and TI Markets}

So many different lay meanings are already attached to the word "technology" that an attempt to generate an inclusive definition would only add to the confusion. Instead, we de- 
velop a working definition for the purpose of this article by reference to the underlying characteristics. ' To this end, we begin with the term "technology." Similar to previous authors, we view it as scientific knowledge applied to useful purposes (e.g., Capon and Glazer 1987; Quinn, Baruch, and Zien 1997). Also termed "know-how," this definition captures the scientific knowledge embodied in a product's functionality, as well as manufacturing and sales knowledge. Products (and services) ${ }^{2}$ are therefore manifestations of know-how. This eliminates the distinction between a product and the technology it encompasses-a distinction that is often difficult, if not impossible, to make (Glazer 1991).

Know-how transforms the business aspects of a market in profound ways; consider, for example, the business of dam building. Dams have been built throughout the world for centuries by applying little-understood principles acquired through experience-an industrial art form. At the turn of this century, the science of soil mechanics was developed, which transformed the business. First, it enabled a much greater variety of dam designs to be considered and compared systematically. Second, the hitherto monolithic product built painstakingly through trial and error became decomposable into subsystems in which independently occurring advances in steel reinforcement, concrete fabrication, watershed mapping processes, and so on could all be brought to bear to deliver an improved dam. This made it impractical for any one firm to be a specialist in all relevant matters. Consequently, heterogeneous firms with differential competencies emerged. Because these subsystems must function properly with one another in a coordinated fashion, standards and interfaces also became salient business issues.

Know-how intensity is not the only basis for studying TI markets. It is useful to contrast it with two alternative concepts that have been used: complexity and speed.

Know-how versus complexity. We do not equate knowhow intensity with complexity per se in design, manufacture, or use. First, customers can use a complex product without being influenced (or even aware) of the underlying complexity (e.g., digital pets).

Second and more important, many markets are complex in both design and production respects and require considerable knowledge, but not of the scientific variety. Rather, they involve craft skills and industrial artisanship, which are different from scientific know-how in their generation and application. For example, violins are complex in their design and manufacture and require skilled craftspeople. However, the relevant knowledge is not science-based, but rather an art form. Unlike scientific know-how, progress in industrial arts is incremental and even regressive on occasion. For example, even today, violin makers are unable to replicate the Stradivarius violins made by a half-blind, virtually illiterate Italian craftsman more than 100 ago.

Complex industrial products also typically are commercialized well before scientific know-how plays a significant

IThis is known as a constitutive definition.

2 We do not make a distinction between products and services because we view them both as offering bundles of tangible and intangible attributes. We use "product" to refer to both products and services. role. Airplanes, steamships, electric generators, and pharmaceutical drugs were all commercial businesses long before their scientific bases were developed (Mokyr 1990). However, the vastly increased design variety, decomposition into subsystems, and rapid introduction of advances illustrated in our dam building example did not occur in these businesses until their scientific bases were developed more fully. Although we might learn useful lessons about intellectual property from artisanship-intensive markets, complexity is an insufficiently discriminating concept.

Know-how versus speed. We do not equate know-how intensity with fast-paced change in demand and/or supply conditions. Rapid change occurs in TI markets, but many other markets exist in which the change of pace is high yet the business is not heavily informed by scientific knowhow. Cultural industries such as music and fashion exhibit fast-paced change, but the change does not indicate scientific know-how. Although we might learn lessons about short product cycles from these markets, speed as a foundational concept for TI markets casts too wide a net

$A$ working definition. Technology-intensive markets are characterized by products that are based on significant amounts of scientific and technical know-how. Complexity and speed of change are corollaries of know-how intensity, not foundational concepts.

\section{Know-How and TI Market Features}

Because know-how is our foundational concept for TI markets, we seek to characterize the relevant features of these markets by appealing to the nature of know-how itself. To this end, we focus on the manner in which know-how is created, disseminated, and used and isolate three relevant aspects of know-how.

\section{Depth of Know-How}

By definition, all markets employ know-how to some nontrivial extent. That said, it is intuitively obvious that its impact depends on its relative magnitude and importance compared with other assets in the same market. When know-how itself represents a substantial portion of the total investment requirements, and hence of the value of the product itself, we observe high levels of research and development (R\&D) spending. Indeed, the U.S. Commerce Department uses this metric to define "high-tech" industries; any industry with double the $R \& D$ expenditures to sales ratio as compared with the average is placed in the high-tech category (Shanklin and Ryans 1984).

As R\&D expenditures become an increasingly large fraction of all expenditures, the supply and demand features of the market itself mirror know-how creation, dissemination, and use. Know-how creation costs are both fixed and sunk. Additional costs to create multiple units of know-how are not relevant. Similarly, dissemination and use of know-how does not use up the stock of know-how. On the contrary, use often improves or increases the existing stock. As we elaborate next, these aspects of know-how processes manifest themselves in two particular features of TI markets. 
Unit-one costs. Markets dominated by investments in know-how feature high "unit-one" cost structures. The cost of producing the first unit is very high relative to the costs of reproduction. To illustrate, the cost of pressing and distributing a CD-ROM are trivial compared with the cost of hiring programmers and content specialists to develop the software code recorded on it. Digital distribution reduces further the reproduction cost (essentially to zero) because customers can and do create (download) their own copies.

Although these fixed development costs appear similar to the fixed costs of investments in physical assets found in many other industries, there are profound differences. For example, an electric utility has a high fixed plant cost, but this only represents an investment in capacity that depreciates over time. In contrast, know-how is never used up and is infinitely extensible. Thus, it is not merely an investment in capacity. Instead, there are supply-side increasing returns to scale in the extreme, which magnifies the classic natural monopoly problem. It is inevitable that one dominant firm emerges, but with the rapid pace of change in these markets, a once-dominant firm may be supplanted by another firm. A useful metaphor for competition is that of a series of races, each won by some firm.

We note that the dominance of unit-one costs is relevant for tangible as well as intangible TI markets. Medical devices and microprocessor firms do not have zero reproduction costs, yet their material and labor cost of production and distribution are of an order of magnitude smaller than the know-how development costs. As we elaborate subsequently, a cost structure dominated by unit-one costs profoundly influences a firm's positioning and pricing decisions, often in counterintuitive ways.

Tradability problems. When know-how represents a substantial portion of the value of the products in question, buyer-seller exchanges are transformed effectively into intellectual property transactions, albeit wrapped within a tangible product transaction. Thus, transactions in TI markets bear all the complications of completing economic transactions directly for know-how (e.g., Teece 1988).

Pretransfer problems emerge because a buyer can value intellectual property best after he or she has acquired it. Sellers are loath to permit buyers to "try it out" because knowledge when acquired cannot be returned or forgotten. Another problem is that the use or possession by one licensee/buyer does not diminish its subsequent availability to another buyer. The original seller can sell unlimited copies at nearly zero reproduction cost. Promises not to sell elsewhere or at lower prices are not credible per se. This makes it more difficult for the first buyer to assess the potential value of the property, especially if he or she might be in subsequent competition with firms buying later from the same supplier. In turn, this makes it more difficult to arrive at a mutually satisfactory transaction.

Posttransfer problems also abound. For example, a buyer may "sit on" a technology to protect its own (obsolete) technology. Such disabilities are exacerbated in international markets because of more fragile property rights. Although trade involving a tangible product, or even an intangible such as a brand name, always accommodates termination as an effective safeguard against adverse outcomes, termina- tion per se is not credible with technology transactions because the buyer retains the relevant knowledge even after termination.

Such problems are magnified when the know-how in question is increasingly tacit in nature. Tacit know-how is defined as know-how that is difficult to convey through documentation (Polanyi 1962) and thus is not readily verifiable by third parties. Examples include process know-how and experience-based human skills. In contrast, codifiable knowhow is amenable to the printed page and can be transmitted easily in patent specifications and the like. Because intellectual property rights rest on third-party verification to enforce patents and licenses, posttransfer problems are magnified with tacit know-how.

In summary, tradability problems characterize TI markets, especially when tacit know-how is prominent. As we elaborate subsequently, these tradability problems have a profound influence on a firm's positioning and compatibility decisions.

\section{Externalities in Know-How}

Externalities are defined as spillovers. Positive spillovers exist in know-how creation, dissemination, and use. Thus, newly created know-how in one area often further enriches an existing stock of adjacent know-how. Similarly, productivity of know-how dissemination and use is enhanced when both the source and the target can build on the stock of know-how that the other possesses. Empirical work has documented these positive externalities in know-how creation, dissemination, and use within industries, across industries, and between academia and industry (e.g., Jaffe 1986, 1989). These externalities create increasing returns in know-how creation and distribution, which make them markedly different from "normal" production and distribution processes that feature familiar diminishing returns properties. The TI markets mirror these distinctions in three respects.

Diversity of technologies. Iansiti and West (1997) observe that interdisciplinary work and integration of technologies are common in TI markets. For example, implantable medical devices depend on microelectronics, nonreactive materials technology, and battery technology. Often, these know-how bases are spread widely across firms, industries, and users. Indeed, as von Hippel (1986) documents, so-called lead users often have been responsible for a lion's share of the commercialized innovations in TI markets. This is unsurprising if we consider the implication of externalities. Because spillovers spur advances at multiple places within groups of interacting communities of firms and users, it is all but inevitable that the breadth of knowhow employed grows over time.

It is not just the diversity of know-how that grows, but also the manner in which new know-how is introduced. Historical accounts note that, as know-how intensity increases in a market, monolithic products become transformed into decomposable systems. This is a fundamentally significant transformation because improvements in one component of the system can be introduced independently of the others. Not only is there greater unbundling over time in TI markets (Wilson, Weiss, and John 1990), which encourages new technology to be introduced into mixed- 
and-matched systems to fit customers' ideal points better, but "enabling technologies" accelerate the diversity of technologies even further.

Enabling technologies typically come from outside the immediate domain of a particular application but ultimately are incorporated to enhance the benefits of the products involved. For example, computing information historically was delivered over localized systems such as mainframe or desktop computers. The development of high-speed Internet links, high-capacity local storage, flat-panel displays, and alternative input devices represents enabling technologies for wide-area, mobile access to this information. Systems become even more diverse as enabling technologies are incorporated.

In summary, as the diversity of technologies increases, products are transformed into systems that offer marketers dizzying possibilities for unpacking them into subsystems and components. Several marketing decisions are influenced directly, including modularity in product design and the components versus systems decision.

Network compatibility. Externalities in know-how creation and dissemination create networks in which collections of users and/or producers coalesce around sets of complementary know-how (Farrell and Saloner 1985). Both physical networks, such as a telephone system, and logical networks, such as the Wintel network comprised of Microsoft operating systems and Intel processors, are created. Compatibility is a significant dimension of these networks.

Compatibility consists of the standards and rules that enable subsystems of products to work together without special modification. It is not an all-or-nothing proposition, but rather a matter of degree. For example, in computer internetworking, protocols such as TCP/IP enable high intrasystem compatibility. At the same time, other areas within the same system (e.g., real-time video streaming) exhibit low compatibility because of differences in the implementation of a common denominator protocol.

There are large gains from compatible networks. Positive spillovers in know-how creation accelerate the rate of progress when a community of users or producers coalesces around common standards. In addition, the larger market size creates lower costs from increased scale and competition. These common standards, or compatibility, regimes vary across TI market networks with qualitative differences in the types observed.

In some TI markets, compatibility derives from a dominant sponsor that achieves "proprietary control" (Morris and Ferguson 1993), whereas a collective or "open control" regime dominates in other cases. An example of the former would be the various interfaces promulgated and controlled by IBM in the mainframe market. In the case of social control (also called open standards), some collective body controls the interfaces. An example is the TCP/IP standards in the networking market. Although there is large analytical literature on network compatibility, there is scant empirical evidence on these matters, as Brynjolfsson and Kemerer (1995) observe in their study, which estimates network externality effects in the spreadsheet market. As we discuss subsequently, marketing decisions about product design modularity are influenced directly by the compatibility regimes in a TI market.
Demand-side increasing returns. Externalities in knowhow creation and dissemination also create demand-side increasing returns in TI markets. Also called a "bandwagon effect," this refers to the situation in which the utility of the item to the $n+1 s t$ adopter is a function of previous $n$ adopters. The classic example is telephones, in that the more people who adopt the telephone, the higher the benefits are to each adopter. The increasing returns often are located in complementary products or peripherals, such as software for computers or prerecorded cassettes for videotape machines. Observe that the bandwagon effect is magnified by greater compatibility within a network of complementary items.

Demand-side increasing returns create fierce winnertake-all battles among competing systems in TI markets. Furthermore, "objectively" superior technology embodied in a firm's product does not dictate success. Market tipping from small historical events can lead to lock-in with a (possibly) inferior technology. The QWERTY keyboard (Arthur 1994) and the Beta versus VHS tape format often are cited as examples of such effects.

These increasing returns arguments are at the heart of the public policy dilemma in the Microsoft antitrust case. As we noted, single-firm dominance of increasing returns markets is almost inevitable. Microsoft's dominance of the Windows marketplace can be justified by appealing to the consumer benefits of the Wintel network that was created as a consequence. The dilemma is that Microsoft's dominance also might have the effect of locking out potential competitors in the future. It is particularly difficult to assess conduct, such as exclusivity contracts and mergers or buyouts by dominant firms, which plausibly grows the incumbent network but also makes it difficult for competitors to enter and challenge with new, competing products.

We note the controversy about the empirical significance of these phenomena. Liebowitz and Margolis (1990, 1995) examine the histories of the QWERTY keyboard and the Beta versus VHS tape format battle and find no evidence of demand-side increasing returns in either case. According to them, in both cases, a close reading of the historical facts does not support the supposed inferiority of the de facto standard. These findings underscore the sparseness of the empirical literature. These controversies notwithstanding, demand-side increasing returns have obvious implications for various marketing decisions. Most notably, a firm's pricing decisions may be tailored to take advantage of increasing returns, an issue we elaborate on subsequently.

\section{Evolution of Know-How}

Unlike physical assets, know-how is "self-regenerative" and evolves, in that one piece of know-how creates the conditions for subsequent pieces (Glazer 1991). Furthermore, the pace of know-how creation can accelerate as individuals and firms become increasingly skilled at exploiting a set of ideas (Romer 1990). It is also path-dependent as a consequence. These positive feedback processes make the trajectory of know-how quite volatile and highly susceptible to small changes. Altogether, these influences make participants uncertain about the timing and trajectory of progress, though it is inevitable that progress will occur. 
Although improved products are always welcome in any marketplace, they are particularly important in TI markets. Know-how-intensive products (e.g., a word processor) are virtually infinitely durable, so repeat purchases are driven primarily by improvements. Thus, expectations of improvements play a crucial role. Three different aspects of expectations are implicated.

Expectations of pace of improvements. The evolutionary aspects of know-how creation previously described virtually guarantee that TI markets feature an ongoing stream of improved and overlapping product generations. Dynamic random access memory chips and microprocessors are two of the most familiar examples of constantly improving generations. An obvious consequence is that the improved versions obsolete older ones while they are still perfectly functional. Customers, recognizing this, begin to form expectations of further and continuing advances in performance (Rosenberg 1976) and decrements in price. They must balance the value (and potential obsolescence) of installed product generations against the potential value of current offerings and future arrivals in making upgrade decisions. The marketer's task of managing transitions between generations obviously is affected by these conflicting influences.

It is important to note that these constant upgrades are not confined to contemporary computer markets. Industrial machinery often exhibits this rapid pace of revisions. To cite an historical example, Kaysen (1956) documents that United Shoe Machinery introduced, on average, approximately 200 changes during the life of an individual model of shoe machine. Its customers clearly anticipated constant revisions in the state of the art.

Expectations of significance of improvements. Pace aside, the magnitude or size of improvements in TI markets can vary quite dramatically. On the one hand, fast but incremental (evolutionary) change results in new generations that are mostly updated versions of earlier ones. On the other hand, fast and significant (revolutionary) improvements result in "inflection points" or technological discontinuities. Truly significant improvements can be competence-destroying as well. For example, the commercial airplane industry currently is moving from 50 years of hydraulic controls to the use of "fly-by-wire" controls, which is a competencedestroying advance for hydraulics specialists.

Customers' expectations about the significance or size of improvements have effects quite distinct from pace per se. Although significant improvements prompt purchases when they arrive, they can have a chilling effect when they are expected imminently. Thus, tailoring marketing decisions about migration in the light of large expected improvements is a crucial element of TI markets.

Uncertainty of expectations. Expectations obviously are not held with certainty. Strongly held expectations result from consistent progress such as microprocessor capabilities, whereas expectations during inflection points are much more uncertain. For example, new techniques (such as "xerogel" bubbles or advances in etching techniques) may increase microprocessor growth rates substantially, but these are only industry conjectures and it is difficult to predict their impact. In other cases, uncertainty may be related to complementary technologies, such as the future capabilities of operating systems and their effects on applications software capability. An interesting example is the computer memory market, in which the evolution of memory device design is far more certain than the improvements in test equipment necessary to fabricate these designs. In industry parlance borrowed from bicycle racing, the chip firms are said to "draft" test equipment firms.

Customer decisions in TI markets are strongly influenced by the uncertainty of their expectations as they migrate through a series of technological advances. As we elaborate subsequently, marketing decisions to support these migration patterns are affected by these uncertainties.

\section{Summary of TI Market Features}

The nature of scientific know-how creates eight features of TI markets, as we show in Figure 1. Unit-one cost structures, intellectual property tradability problems, highly diverse technologies, network compatibility issues, demandside increasing returns, and customers' expectations about the pace, size, and uncertainty of improvements are all salient in TI markets. That said, we reiterate that these eight features do not define a TI market. The value of specifying these features lies in explicating links between them and important marketing tasks in these markets. We turn to this task next.

\section{Marketing Decisions in TI Markets}

We focus on four specific issues and begin with the most fundamental decision in a TI market: what to sell. We label this the vertical positioning decision. We then consider two product design decisions: choosing a platform design versus a conventional targeted product design and whether to use a modular system design or the traditional optimized product design. The third major decision is the design of transfer rights, which can range from complete transfer of ownership to limited per use rights. Finally, the migration assistance decision to move customers from one product generation to another rounds out the set.

Our choice of these issues is driven by three considerations. First, the sheer intensity of know-how in TI markets creates and/or magnifies greatly the number of decision alternatives for these issues, whereas the choices are much more constrained in conventional settings. Second, conventional wisdom from other settings often does not carry over for these decisions. Put differently, they have surprise value. Third, they represent live research opportunities, because empirical work on these matters is scarce.

We identify two important limitations. First, we eschew competitive strategy considerations. Competing in a TI market involves commercializing technological know-how. As such, firms differ greatly in their technological competence. Nevertheless, we do not address the effects of this heterogeneity in resources and capabilities that enable or detract individual firms from making these decisions. Likewise, we do not address the effects of the alternative means by which firms obtain these resources (e.g., internal development versus acquisition). Stated differently, we are not addressing the 


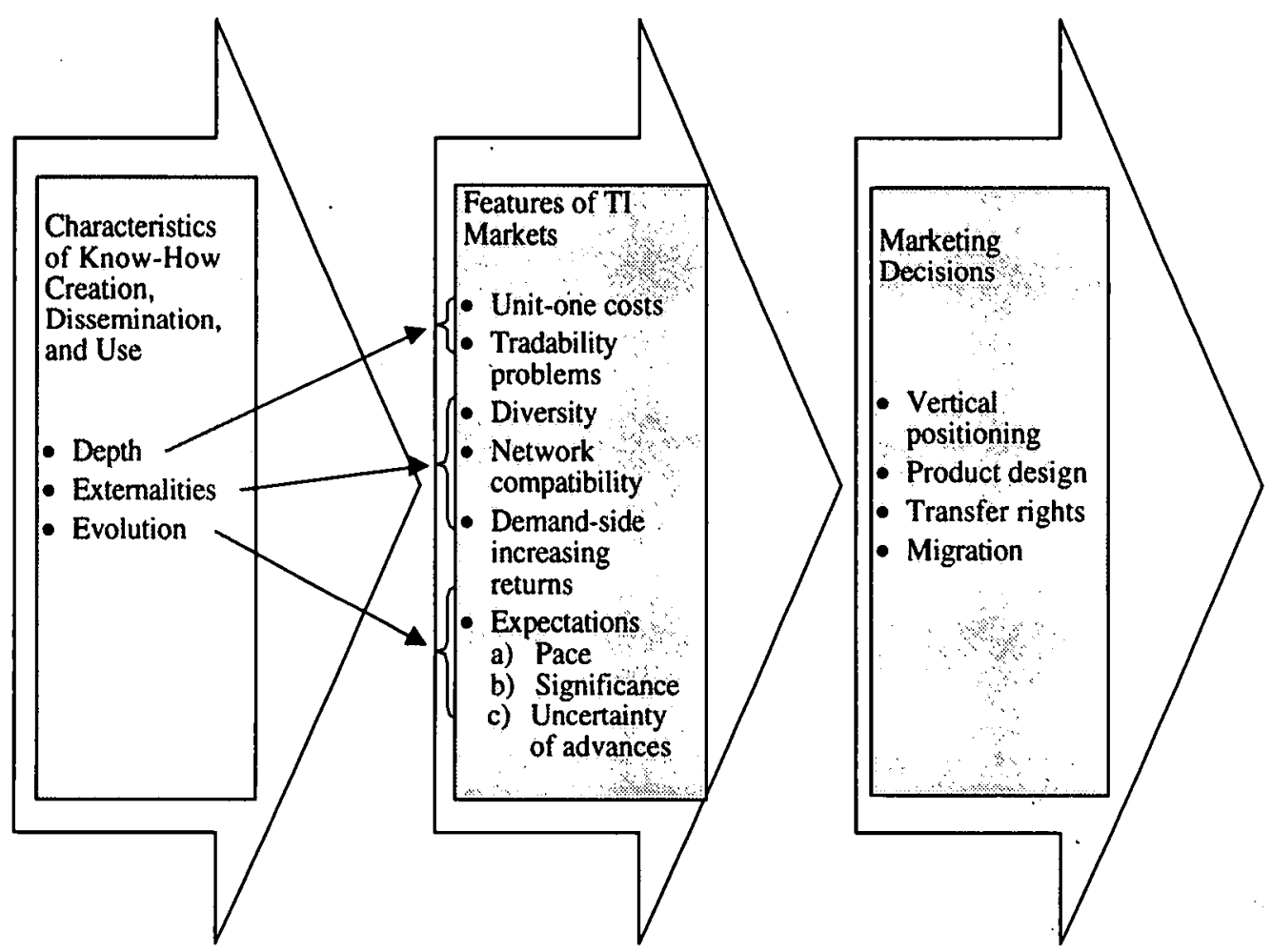

strategic constraints imposed by the firm's resources or the comparative merits of alternative organizational forms.

Second, though we emphasize main effects in our propositions, we do not mean to imply that these decisions are linear, sequential decision processes. Marketing decisions are simultaneous processes subject to various interactions. Our discussion is an initial attempt to represent, in a parsimonious way, the complexity of marketing in these settings.

\section{Vertical Positioning Decisions}

All products in a TI market start with some valuable knowhow. The firm that owns the know-how must fashion a selling strategy for converting it into revenues. We offer the following continuum for framing the options.

$A$ continuum of locations. The alternative vertical positions are depicted along the continuum in Figure 2, which orders them by the funds expended by the buyer beyond the acquisition cost of the focal purchase. These funds are expended on realizing the core product and/or purchasing complementary items, services, and training so as to derive the intended benefits from the focal purchase. At the top (high) end of the continuum, firms sell know-how directly. For example, chemical firms often sell (or license) the rights to a specific molecule to downstream producers. This vertical position is the furthest from final use, in that the item sold requires the greatest additional expenditures of funds by the target after the focal transaction to realize the final intended benefit.

One step removed from selling know-how directly is the sale of a proof of concept. Here, a prototype or pilot plant is developed to establish that the know-how can be made to
FIGURE 2

Continuum of Vertical Positions

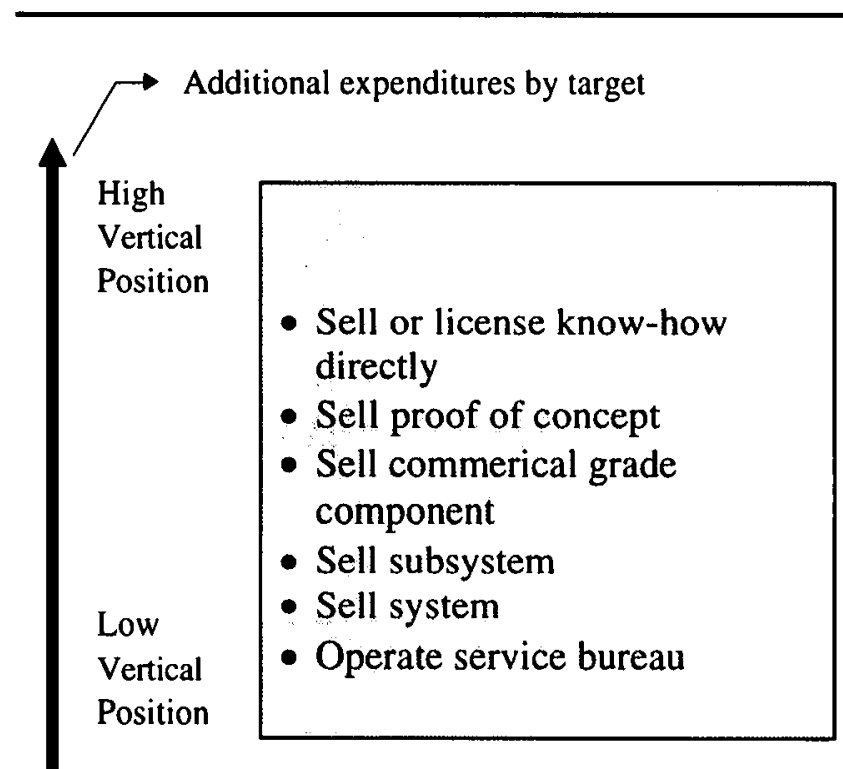

work. Further down the continuum are sales of commercialgrade components to original equipment manufacturers. Even further down are sales of final products or systems that contain all the essential components, so that they are ready for service out of the box. Finally, at the bottom (low) end of the continuum, firms operate service bureaus that deliver 
the intended benefits directly, with no additional expenditures required for complementary items.

To illustrate these possibilities, consider the desktop laser engine technology developed by Canon in the early 1980s. Canon could have sold (or licensed) the know-how directly. It could have sold components (bare laser engines) to laser printer manufacturers. It could have sold print subsystems (the laser engine combined with the required lowlevel software) to printer systems firms such as QMS or Hewlett-Packard (HP). It could have sold a complete system (the laser engine combined with low-level software and a higher-level page description language such as Postscript or PCL) that worked right out of the box to end users. Finally, it could have established print service bureaus that used its equipment.

Historically, the most common vertical positions in the economy have been close to the final use level. We infer this from the aggregate size of royalty revenues, which have been negligible compared with aggregate product sales revenues (much less than $1 \%$ in TI markets). Royalty revenues in these markets have been smaller than even the R\&D expenditure itself (Thurow 1997).

However, this picture is changing rapidly. Firms increasingly are trying to realize revenues from know-how using different vertical positions. For example, Texas Instruments, which previously relied on selling components and final products, in recent years has received more in licensing fees than its entire operating income provides (Thurow 1997). Multiple vertical locations are also a growing phenomenon. Returning to the laser printer market, Canon simultaneously sold printer subsystems to QMS, HP, and Apple, as well as a ready-to-use laser printer (the LBP4) to end customers. More recently, IBM has become an aggressive vendor of components such as disk drives and chips in addition to their traditional systems business.

Vertical positioning is not vertical integration. Vertical positioning is a more fundamental decision than vertical integration. The latter decision is predicated on what is to be sold. After deciding what to sell, a firm can decide whether to manufacture or source it. For example, HP's decision in the laser printer market can be contrasted with its choice in the inkjet printer market. It sold complete systems in both cases. However, its vertical integration strategies were drastically different. Hewlett-Packard purchased laser print subsystems from Canon but manufactured its own inkjet print subsystems.

Vertical positioning is not value chain position. As per Porter (1985), we can define a firm's position in a value chain as its set of internalized activities within the overall set of activities undertaken by all the relevant firms. In contrast, its vertical position is not defined over activity sets. Rather, it is defined over the stock of relevant know-how that it owns or controls and the manner in which it chooses to transform this know-how into revenues. To illustrate the difference, suppose that $A$ manufactured a complete printer for B using B's know-how and design. A adds its manufacturing process know-how to the mix. A's vertical position is not at the finished product level, though it manufactures the complete product. Rather, A's vertical position is at the know-how level because it has elected to sell its manufacturing process know-how directly.

Favorability of different vertical positions. Although know-how intensity leads to decomposition of monolithic products into subsystems and components, which creates multiple vertical positioning possibilities, it is not the case that all these positions are equally attractive. Farrell, Monroe, and Saloner (1998) develop analytic models to show that competing at one level (say, components) is different than competing at another level (say, systems) in the same product category. Both strategic interaction patterns and profitability consequences are different.

We observe that most of the profits are captured by firms located at one or two favored locations and that these locations shift over time. For example, in the personal computer industry, most of the profits currently flow to firms that compete at the component and subsystems levels. Intel sells microprocessors as components and motherboards as subsystems, whereas Microsoft sells its operating systems and applications as subsystems and components, respectively. In contrast, in the mainframe computer industry, most of the profits flow to firms such as IBM and NEC, which compete at the systems level. Several factors are responsible for different vertical positions being favored across markets.

Diversity effects. Highly diverse technologies in a TI market make it increasingly unlikely that a single firm can maintain its lead on all the relevant technologies across all the components or subsystems of the final product. Put differently, firms located at lower vertical positions find themselves handicapped in cost and/or quality dimensions in their efforts to keep up. In contrast, locating at higher vertical positions enables firms to specialize and, therefore, deliver lower costs or higher quality components or subsystems. This logic leads to the following testable proposition:

$P_{1}$ : Greater diversity of technologies favors higher vertical positions.

Because all TI markets are characterized by some diversity of technologies in final products and such diversity tends to increase over time, there is a powerful trend toward componentization. What might offset the pull toward locating further away from final use?

Compatibility effects. Mixing and matching compatible components appeals to customers because it makes it easier for them to find a system suited to their own idiosyncratic needs (closer to their ideal point, in product-map terminology). It also appeals to producers because it allows them to specialize on a narrower range of relevant technologies, especially when these technologies are diverse.

In contrast, poor compatibility regimes raise the cost of putting together an acceptable system or even render it infeasible. Selling know-how or individual components is difficult enough, but selling new, improved components is even more difficult. A current example is the high-capacity (e.g., 120 megabyte) floppy disk from Imation. Because Imation does not produce disk drives itself and existing drives are incompatible with the new disk, it must persuade drive manufacturers to produce and market compatible high-capacity drives. In contrast, Iomega faces an easier 
task in marketing its improved zip products because it controls both the drive and the disks. Accordingly, we propose the following:

$P_{2}$ : Poorer compatibility regimes favor lower vertical positions.

Demand-side increasing returns effects. Lower vertical positions also are handicapped when there are bandwagon effects from network externalities. The consequences of locating at a "wrong" vertical position can be demonstrated vividly by the difficulties faced by Apple Computer, which located itself at a low vertical position (system level). Its emphasis on its proprietary hardware standards over de facto open standards built around the IBM personal computer platform made for a winner-take-all battle for the attention of third-party hardware and software developers. Specialist suppliers with state-of-the-art know-how increasingly are deserting Apple for the Wintel network. In turn, this weakens the Apple product itself as the firm falls further and further behind in keeping its subsystems up to date.

$P_{3}$ : Greater bandwagon effects favor higher vertical positions.

Tradability effects. Perhaps the biggest deterrent against locating at high vertical positions is that the know-how might not be sufficiently tradable. Recall that intellectual property transactions involving tacit know-how are fraught with difficulties. In terms of the vertical position decision, this virtually rules out the top of the continuum. However, if the firm is located lower on the continuum and tacit know-how is wrapped into a component, subsystem, or even an entire system, the target is indifferent to the tacitness and only needs to assess the benefits of the product that embodies the know-how itself. Accordingly, we propose the following:

\section{$\mathrm{P}_{4}$ : Greater tacitness favors lower vertical positions.}

It is worth noting that tradability is not a fixed characteristic of the stock of know-how. For example, high bandwidth information technologies, including live computerized documentation, expert systems, and multimedia (to simulate direct interaction) can enhance tradability to the point that an intellectual property transaction becomes feasible. Alternatively, these firms can accept the extant tacitness but target those buyers that face smaller transfer problems.

The most compelling target for a intellectual property transaction involving tacit know-how is a customer that already possesses virtually the same know-how or is capable of producing it in short order. This is counterintuitive, and an illustration will serve to fix the idea.

Consider process engineering and management consulting firms. Plainly, these firms are located at high levels of the vertical positioning continuum, but the know-how being sold is tacit. How do they overcome the difficulties alluded to previously? Briefly, they employ a targeting strategy quite different from the conventional dictum that customers with the highest value-in-use (reservation price) are the most attractive targets.

Contrast two prospective buyers: a sophisticated buyer with a large, in-house engineering (or management) staff that is skilled in using the tools and methods employed by the outside consultant versus another buyer that lacks such resources. Conversations with consultants confirm that their best targets are sophisticated firms that could actually do the job with in-house resources. Why?

The absorptive capacity of the unsophisticated firm is lower in spite of its greater need (and presumably greater value-in-use) for the service in question. Thus, the sale is more difficult to close. Similar unusual effects are found in the use of publicly funded research by private industry. The intention of the public funding is to assist firms that have inadequate in-house research resources. However, firms with large research budgets and staff are the most intensive users of academic and public-sector research. Thus, publicly funded work intended to help resource-constrained firms actually increases the divergence between firms. Accordingly, we propose the following:

$P_{5}$ : Sellers of tacit know-how favor buyers that possess similar know-how to themselves over dissimilar buyers.

\section{Product Design Decisions}

Regardless of the vertical position(s) chosen by a firm, it must decide on the most appropriate design for the product. Contemporary marketing exhorts designers to listen to the voice of the customer by collecting information on target customers' needs and preferences. After segmentation, each segment's needs are transformed into product design specifications intended to deliver the identified needs. The designer's task is to balance costs with the quality and performance demanded by customers. The desired outcome is an optimized design that hits the segment's sweet spot or center of gravity

This conventional philosophy of customer-driven product design faces two unique challenges in TI markets. First, should a firm design targeted products to hit a segment's sweet spot, or should it design a common core with different versions for different segments (a platform strategy)? Second, should the firm optimize design, given costs and customer needs, of the target as per the conventional philosophy, or should it deliberately modularize the design?

Target platform or target product decision? A platform product strategy entails offering several variants to different segments, each of which is based on a single core design. In contrast, with targeted products, each identified segment has a product built for it. Those TI markets that are dominated by unit-one costs make the platform strategy more attractive. The idea is that if incremental costs of variants are relatively small compared with the core design, it pays to proliferate versions of a common design to reach segments with different willingness-to-pay levels, because this adds incremental revenues (Varian 1997). In contrast, trying to reach each small segment with tailored products is expensive with unit-one cost structures.

It is crucial to design the right core platform that then can be "versioned" relatively cheaply. In this regard, the philosophy of designing a product to maximize its appeal to a segment is not very useful. Instead, the platform (called 
the "reference design") 3 version should be designed for the high end of the user market and incorporate as many of the desired features as needed for this segment. This is counterintuitive because the high end is unlikely to be representative of the general user. Nevertheless, large fixed development costs are more likely to be recovered from developing a design with the attribute levels desired by the segment with the highest willingness to pay. Then, lower-priced versions can be sold at much lower prices, given a modest incremental cost. It is the asymmetry that makes this decision unique. Subtraction of features is a low incremental cost activity, given existing stocks of know-how, but addition of features most certainly is not.

A practical way to implement this is to use lead users as the principal voice of the customer (von Hippel 1986). A firm in the surgical dressing business used military combat hospitals as their principal source of customer input, even though the product was targeted at civilian hospitals. We reiterate that representativeness is not an issue, so traditional sampling notions are irrelevant. Likewise, concerns that lead users might not foreshadow mass-market needs are irrelevant, because the platform design can be versioned down easily. Instead, it is critical to capture the high-end requirements adequately.

$P_{6}$ : Dominance of unit-one costs favor platform designs over optimized designs.

There are some curious conșequences of a platform design. Because mass-market versions are created by stripping away features from the high-end version and the product is not tailored to deliver the combination of features that the middle market desires, it is inevitable that the middle market will be less satisfied than will high-end customers. We speculate that measured customer satisfaction will be lower with a platform approach.

Modular or optimized designs? Recall that know-how transforms monolithic products into systems. We distinguish two system design strategies. Traditional engineering design employs constrained optimization methods "to obtain the highest level of product performance within a cost constraint" (Sanchez and Mahoney 1996, p. 65). This approach leads to systems "composed of highly integrated, tightly coupled components." In contrast, modular systems are designed with a view to isolating components from one another. "Standardized component interfaces that define functional, spatial and other relationships" are "not permitted to change during an intended period" (Sanchez and Mahoney 1996, p. 65). Sanchez and Mahoney cite many examples of modular designs, including the Boeing 777 aircraft and

\footnotetext{
3One odd feature of this version is that the costs of producing lower-end products actually are higher than the costs of higher-end products if the higher-end product is the initial design. To illustrate, an implantable cardiac device offers lower-end versions that consist of the exact design as the higher-end product with certain features disabled, which incurs a small, additional manufacturing cost. It is the relatively small size of these additional costs compared with that of serving new segments that allows such deliberate waste to be nevertheless efficient overall.
}

Chrylser's LH platform. When is each design approach more appropriate?

Diversity effects. A high diversity of technologies enhances the likelihood that improvements will emerge in places outside the focal firm's reach or control. This requires the firm to maintain a flexible position. Adaptability would be compromised were the firm to decide to use an optimized design approach. Why?

With optimized designs, the tightly coupled components result in large numbers of changes that ripple through the system when one change is made in one component. Contrast functional specifications with design specifications; for example, specifying a commercial door's fireproofing requirements as needing two inches of fiberglass filling and a certain type of glue (design specifications) is considerably less flexible than specifying that it should resist a 500 degree flame for 15 minutes (a functional specification). In the latter case, an improvement in the know-how of gluing the parts of a door together can be dropped in much more easily. The automobile industry is another example of a shift toward functional specifications. Component suppliers are able to take on more of the know-how development work. Accordingly, we posit the following:

$P_{7}$ : Greater diversity of technologies favors modular designs over optimized designs.

Tradability effects. As we discussed previously, when tradability problems are high, firms are faced with increased difficulty in transferring the relevant know-how to other parties. Modular designs presuppose that the nuances of the know-how can be captured and transferred through published interfaces so that development work on improvements can proceed independently across firms. To the extent that tacitness precludes this, modular designs are less useful. Accordingly,

$P_{8}$ : Greater tacitness favors optimized designs over modular designs.

Uncertainty effects. With more uncertainty about the evolution of technology, it pays to maintain flexibility because advances in one part of a system can be accommodated without scrapping the entire system. Modularized designs are much more capable in this regard. In effect, customers attach "option" value to such designs because it permits them to switch components at a later point if needed. As Grenadier and Weiss (1997) show, the value attached to options increases with uncertainty. Accordingly, we posit the following:

$P_{9}$ : Greater uncertainty about the evolution of technology favors modular designs over optimized designs.

\section{Transfer Rights Management}

Recently, Intuit's chief executive officer, Scott Cook, remarked that "a hundred years ago, musicians, playwrights, athletes, and actors died poor. Now, they die rich" (Bollier 1998, p. 23). He attributed the change to the development of new technologies for distribution and sale of know-howintensive products. Simply put, many more people can see a 
FIGURE 3

Continuum of Transfer Rights

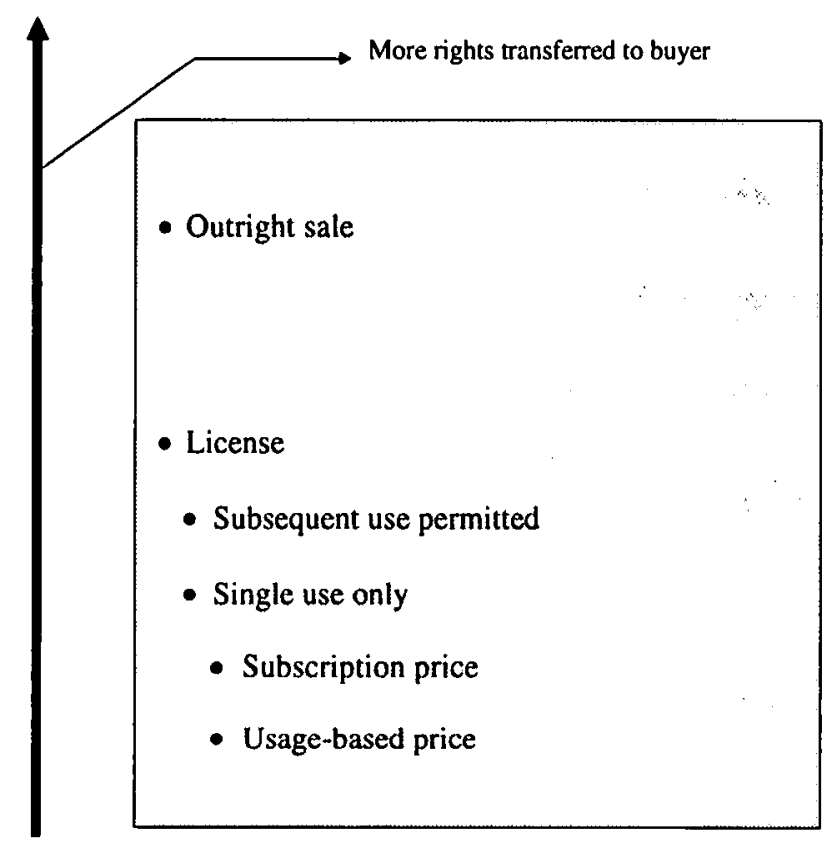

movie or read a book when reproduction and distribution costs shrink. These new distribution technologies also multiply the ways in which the revenues from intellectual property can be generated. We offer the following continuum for framing this issue.

A continuum of transfer rights. Distribution and selling options for know-how-intensive products can be organized along the transfer rights continuum depicted in Figure 3. At one end, there is a complete transfer of rights so that the buyer owns the product completely and can do whatever it pleases. At the other end are licensing arrangements that are highly restrictive in terms of volume, timing, and purpose of usage. An example would be a micropayment scheme as is envisioned for Java applets. ${ }^{4} \mathrm{~A}$ user would download an applet as and when needed, which would self-destruct after the paid-for usage expired.

A naïve view of transfer rights might assume that a seller should always maximize its rights and transfer as few rights as possible. In this view, micropayment licensing schemes, if feasible, are always better than outright sales. However, this is myopic because buyers are willing to pay more for greater rights transferred to them. Thus, the point is not to minimize transfer rights per se but to maximize profits by choosing the right amount of rights to transfer. How is this accomplished? It is difficult to consider the multiplicity of formats simultaneously, so we simplify the matter as follows: We examine three pairs of alternative transfer rights formats in TI markets, that is, outright sale versus license, usage restrictions, and per use versus subscription pricing.

\footnotetext{
4Java is a computer programming language that permits programs to be created on one type of computer but then can be executed on many other types of computers.
}

Outright sales versus license. In a world of certainty, transfer rights decisions are of little significance. Both parties know the value of the product, and no greater efficiency attaches to any particular configuration of transfer rights. Imposing restrictions simply reduces customers' willingness to pay, and vice versa. Uncertainty changes the game for the buyer and seller. It makes it more difficult to assess the value of the applications of the technology at the time of transfer. Thus, outright sales are more difficult to conclude because the net present value over the horizon must be estimated. In contrast, short-term licenses over specific fields of use can be estimated more readily. Subsequent fields of use can be estimated as uncertainties resolve themselves. This reduces the revenue stream from the current transfer, but this trade-off becomes worthwhile with greater levels of uncertainty.

$P_{10}$ : Greater uncertainties about the evolution of the technology favor licensing over outright sales

Individual or subsequent use? A large number of specific licensing formats can be organized usefully into (1) those that restrict the target's rights to transfer the product to subsequent uses or users versus (2) those in which such transfers are permitted. For example, computer language compiler program licenses often require that a subsequent user of programs produced by a direct customer of the compiler product must pay royalties to the compiler firm. In contrast, a subsequent use license permits the original customer to produce programs with the compiler and sell it without further payments. Divx (digital video express) and DVD (digital versatile disk) technologies embody this distinction as well. Although the technical capabilities of these competing, second-generation CD-like devices are remarkably similar, Divx incorporates an encryption system, thus enabling payper-view restrictions. When might such restrictions be more useful?

Recall that unit cost structures create large fixed costs of producing the first product compared with the low costs for reproducing subsequent units. When customers also can reproduce copies at low cost, producers face two broad options. They can charge a high price to a smaller number of intermediate customers (e.g., video stores) but permit them to release their product to their end customers or allow sharing among multiple users (e.g., site licenses). Alternatively, they can charge a lower price to individual end users but not permit sharing or retransfers. Varian (1997) argues that the choice turns on the ease with which customers can take on the task of distribution and/or sharing. When customers' costs for such tasks are lower than the firm's costs, the firm is better off using the high-price sharing option. The idea is that the lower cost of self-production increases customer valuation, so a higher price offsets the lower unit sales.

Operationally, this means selling to groups either directly or indirectly. For example, networking has dropped the costs of sharing software dramatically in recent years, especially in business locations. Thus, site licenses with rights to copy become more attractive than individual shrink-wrap licenses. Another example is the case of a medical device such as magnetic resonance imaging (MRI) machines. Suppose there are large hospitals that have a higher willingness 
to pay and smaller hospitals, which do not use the device as intensively, that have a lower willingness to pay. The firm can enhance its market by thinking of creative ways in which the smaller hospitals could share the product through some form of leasing arrangement. One way to accomplish this is to market a mobile version of the MRI product that is literally moved from site to site on a trailer. At the same time, it could sell a fixed-site version directly to the larger hospitals. In summary, we posit the following:

$P_{11}$ : Dominance of unit-one costs favors subsequent use formats over individual use formats.

When firms sell TI products with tradability problems, customers face inherent difficulties in retransferring or sharing the product, even if they desire to do so. Consequently, even if the firm permits retransfers, little additional value is attached to this right.

For example, suppose an engineering firm licensed the right to use a catalyst in a chemical process to a customer. The effectiveness of a catalyst often depends on the (tacit) skill of tweaking the chemical reaction process. If the target possessed a site license for the catalyst for all its plants, it would nevertheless require the assistance of the source to tweak it successfully in each case. Thus, the source is better off designing single-plant licenses and possibly even fieldof-use restrictions. Otherwise, it is likely to face uncertain levels of costly technical support calls. The idea is that valuation (and therefore exchange) is facilitated by defining its scope of use. Thus, we posit the following:

$P_{12}$ : Greater tradability problems favor individual use formats over subsequent use formats.

Per use or subscription prices? Usage-based pricing discriminates customers in a more fine-grained manner than does subscription pricing. Greater price discrimination, if feasible, is normally more profitable. However, this is complicated in TI markets by increasing returns effects and uncertainty.

When the value of a product to a prospective customer is increased by a larger number of other users, there is a premium on gaining an early lead over competing products because markets can "tip" in a product's favor. Encouraging usage by existing customers is one way to leverage these externalities. Field experiments in the telephone industry (Fishburn, Odlyzko, and Siders 1997) show that subscription plans increased customer usage volume significantly more than usage-based plans. Usage-based pricing deters experimentation with unfamiliar products and, thus, inhibits the growth of the network.

$P_{13}$ : Greater increasing returns effects favor subscription price formats over per use price formats.

Micropayment schemes that represent finely grained usage pricing have been advocated in several high-tech contexts. For example, digital watermarks permit passive monitoring over a network of the number of times an image has been viewed. Likewise, the network computer promoted by Oracle and others is supposed to feature consumers downloading applications as needed and paying for them on a per use basis. We suggest that firms that face increasing returns to scale in their market need to grow the network and thus may be better off eschewing the pay per use format, even if technology enables them to do so.

Rapid and uncertain changes make information more time-sensitive (Weiss and Heide 1993). This includes even the value of knowing prior usage patterns. Thus, knowing how much a current generation product was used (and valued) is not much help in determining the need for the next generation product. Furthermore, advances in technology often impose steep (re)learning curves on customers. These influences combine to create uncertainty among customers about their needs and the value or utility of a product over time.

As such, we can expect them to act in a risk-averse fashion and therefore pay for "insurance" in the form of a subscription price. Strong evidence of this risk-aversion effect comes from field trials of use-based pricing for telephone use. Even when their immediate past period calling patterns show they would profit from a usage-sensitive plan, customers strongly prefer flat rate, subscription-style plans, especially as more uncertainties are introduced.

$P_{14}$ : Greater customer uncertainty favors subscription price formats over usage price formats.

\section{Migration Decisions}

Overlapping product generations are the norm in TI markets. Norton and Bass (1987) document that successive generations typically arrive when the current generation's sales curve still is rising and may continue to rise for some time. Both the launch of a new generation and the withdrawal of the old become equally significant decisions with overlapping generations, as does the decision of whether to help prior customers migrate from one generation to another. This decision is complex because of the tensions among a firm's desire to provide state-of-the-art technology through a continuing evolution of new product generations, customers' expectations and fears of obsolescence, and the "footprint of the past" from the installed base's commitments to prior generations of the firm's technology. We offer the following continuum for framing this issue.

A continuum of migration options. In Figure 4, we depict the options for managing overlapping generations. It orders the alternatives by the degree to which they enlarge the customer's options. At the bottom, the firm simply withdraws the older generation as soon as the new one is launched, and no special assistance is offered to the installed base. The customers' options are very limited. Lack of parts and service for the incumbent installation may force a decision sooner than they would have liked.

At the next level, the firm withdraws the older generation as soon as the new one is launched, but migration assistance is provided to the installed base. For example, it could provide technical help, allow trade-ins, or provide backward compatibility through product design, patches, or gateways. The customers' options have enlarged, so that they can continue upgrading and maintaining the old version and move to the new version at some later point.

Further up the continuum, the firm sells the old and new generations together for an announced period, following 
FIGURE 4

\section{Continuum of Migration Options}

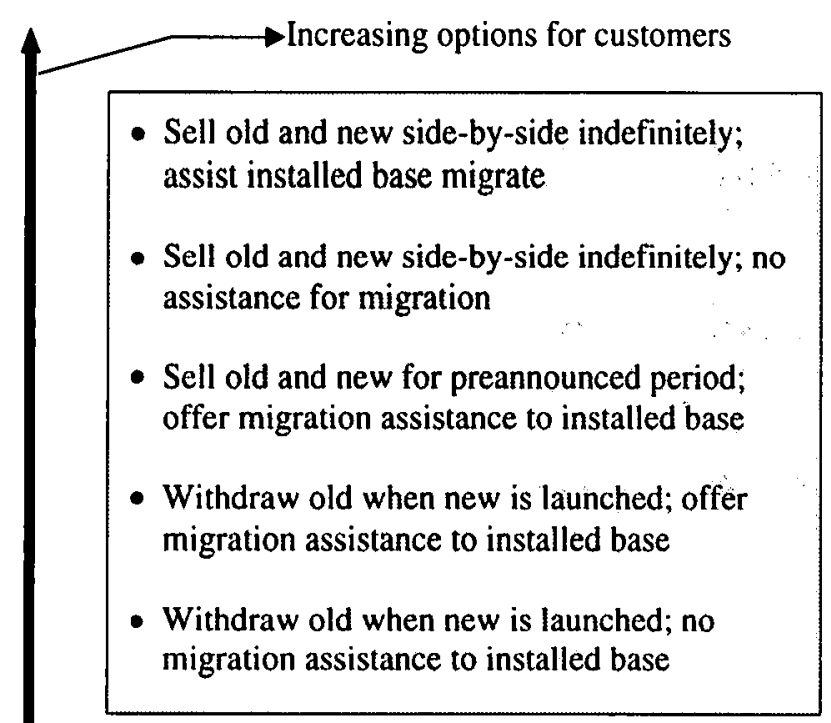

which the old generation is withdrawn. This increases customer options even further. Consider a customer with an installed version (A) that is older than the latest one for sale (B). Even after the next version (C) is launched, this customer still has the option of moving from $\mathrm{A}$ to $\mathrm{B}$ and then to $\mathrm{C}$ later or to go from A to $\mathrm{C}$ directly.

Finally, at the top of the continuum, the firm sells both generations as long as the market desires them and provides migration assistance to the installed base. What is the right choice? We rely extensively on the real options model by Grenadier and Weiss (1997) to develop the arguments that follow.

Expectations of fast-paced advance. When customers expect rapid, albeit small, advances, it pays to increase their options. Customers who anticipate a rapid pace of advances tend to wait for price declines and/or bug fixes in newly launched versions. Providing migration assistance to the installed base mitigates such stalling. These customers also tend to bypass completely ("leapfrogging" in Grenadier and Weiss's 1997 terminology) newly launched versions in anticipation of some yet-to-be-launched future version, as is documented by Weiss (1994). Such behavior also is mitigated by migration assistance. Absent such assistance, firms will find their revenues swinging wildly, with detrimental effects on funding developmental activities.

$P_{15}$ : Greater anticipated pace of advancements favors greater customer migration assistance.

Effects of significant advances. Recall that technological innovations can be evolutionary or revolutionary. When significant technological improvements are anticipated, customers expect sharp breaks with the past and know that smooth upgrades are not possible. Grenadier and Weiss (1997) show that few customers wait to purchase an older generation of the product, which will be made highly obsolete, at a reduced price when they anticipate a significant new version being launched. In short, there is less to be gained by keeping options open. Consequently, it makes sense to move toward the bottom end of the migration assistance continuum. This is a fairly counterintuitive result, because we might expect that firms wish to assist their installed bases with the anticipated disruption. Although subsidies are always welcome, the harsh reality is that customers' existing assets have been destroyed in a Schumpeterian sense.

$P_{16}$ : Expectations of significant changes favor less migration assistance.

Uncertainty of future evolution of technology. When uncertainty of the future evolution of technology is high, a compelling case can be made to increase customer's migration options. Uncertainties are greatest when a qualitatively different technology is introduced but its prospects are highly uncertain. For example, in 1987, ROLM5 introduced the Sigma PBX, which ran at 8 kilohertz, unlike its previous CBX product line, which ran at 12 kilohertz. Because of ROLM's history of assiduously maintaining backward compatibility, this break with the past was certain to generate high uncertainty among its customers.

Highly uncertain customers resort to various ploys to resolve their uncertainty. One tendency is to bypass the version closest to their installed version to wait for an even newer version to be launched. Another tendency is to wait for the prices of current generation products to decline before purchasing, so that the lower price acts as an insurance policy. Selling both the old and the new generations for an extended period of time is especially warranted in these circumstances, especially if the older generation can be sold at reduced prices to encourage customers with even older installed versions to migrate to the next step.

\section{$P_{17}$ : Greater uncertainty among customers about technology evolution favors greater migration assistance.}

\section{Conclusions}

\section{Changing Marketing Practice}

We believe our nomological network raises some serious challenges to practice guidelines extrapolated from conventional markets. For convenience, consider the marketing process as consisting of four broad stages: (1) served-market definition, (2) product development, (3) attracting customers, and (4) retaining customers. Subsequently, we contrast the propositions from our framework with conventional heuristics at each of these stages.

Consider the served-market definition stage. We argue for the fundamental importance of the what to sell decision by offering the vertical positioning continuum. To the best of our knowledge, this is a completely new issue. It is not just a relabeling of the value chain idea or the vertical inte-

5ROLM: The Sigma Introduction, Harvard Business School Case 9-590-082, Revised January 1997. 
gration decision. It challenges the bias that final product (downstream) positions offer more scope for differentiation and more profits than intermediate product (upstream) positions. The enormity of Intel's profitable component branding effort, with a budget among the largest in the world, is an illustrative example of the fundamental importance and competitive significance of upstream positions in TI markets. They are not just anonymous suppliers anymore.

At the product development stage, in certain circumstances, the conventional view of optimizing a product for the needs of a segment gives way to a reference platform designed to meet the most demanding customer segment. This is a major challenge to our thinking about customers and their role in marketing, because the high-end segment tapped to provide the voice of the customer is not the target customer and is, by definition, not representative of the target.

At the customer attraction stage, the conventional view is driven by the heuristic that differentiating the product to heighten its uniqueness enhances product value. Modular design principles challenge this view directly by inviting potential competitors to drop in their components. Incorporating these viewpoints simultaneously into decision making represents a qualitative shift in our thinking about competition in a product market space.

Finally, with respect to customer retention, the contemporary agenda has focused on speeding up new product launches, improving cycle times, and so forth. Withdrawal decisions about old products appear to be an afterthought. We challenge this emphasis by placing launch and withdrawal decisions on an equal footing on the migration continuum.

To the manager who is skeptical about the empirical robustness of our propositions, we direct attention to the value of the nomological network itself. Specifically, the eight features of TI markets and the three continua explicating the options for vertical positioning, transfer rights, and migration assistance are useful in their own right. They frame the decision space better, even if the manager is unprepared to buy into the propositions him- or herself. The structure affords the opportunity to attend to these issues systematically rather than piecemeal.

\section{Motivating Empirical Research}

We began this article with the argument that TI markets are important and deserve greater attention from marketing. It is striking that extant theory is concentrated heavily in the game-theoretic modeling tradition, despite the prevalence of mentalistic constructs, such as expectations, that are so central to the area. The paradigmatic base is quite narrow. That said, perhaps the theoretical results are robust. If so, empirical verification is the key, but this has lagged far behind. More troubling, the scant evidence to date does not provide support for effects often taken for granted. We previously observed that Liebowitz and Margolis's $(1990,1995)$ examination of the history of the two most (in)famous examples of network externalities (QWERTY and Beta versus VHS) found no supporting evidence. Similarly, leapfrogging is part of the marketing vocabulary about TI markets, yet we are able to locate only a single empirical study on that topic (Weiss 1994). In short, this is a rich and untapped empirical area. Our hope is that our nomological network will inspire future work.

\section{Final Comments}

In developing this article, we often were struck by the extravagance of the previous claims (e.g., Dyson 1995). Even academic work has a tendency to proclaim that the lessons of history may not be relevant. Our own view is that the levels of variables in TI markets may have changed, but the basic causal effects are not new. To demonstrate this, consider an historical perspective on two often-discussed issues about TI markets: components and compatibility.

Contemporary TI markets so commonly are endowed with multiple sources of compatible, interchangeable components that it is worth remembering that the ability to mix and match components has existed since the Civil War. Advances in machining technology in that period were the keys to "unpacking" the production of rifles. Rifle components could be made to sufficiently exacting specifications, such that they could be produced separately and assembled into a functioning firearm. Thus, compatibility became a central concern in many product markets long ago. In marketing, Reddy (1987) reminds us that issues of industry standards have been debated in the literature at least since the turn of the century.

Economic historians studying bygone eras often have noted rapid and volatile improvements in technology. For example, such change characterized marine engineering between the World Wars, and it had profound effects on the adoption of incandescent lighting (due to leapfrogging behavior) during the 1880s (Passer 1953). Rosenberg (1976) provides several other historical examples of rapid and volatile technological change.

To us, these historical accounts suggest that the existence of these features is not new. Rather, they have established and will continue to increase their prominence and significance. Why? Know-how continues to expand at an increasing rate, fueled by continued global communication and infrastructure improvements and the natural self-regenerative nature of know-how. Thus, the following predictions are fairly conservative:

-Unit-one cost structures increasingly will dominate decision making in marketing, thereby increasing the variety of pricing and rights transfer formats that need to be considered;

-Products increasingly will be decomposed, which will open up many new, fine-luned vertical positioning options for marketers; and

-The life of product generations will continue to shrink, and migrating customers across product generations will become increasingly important.

Attending to these types of questions and building on an understanding of TI markets promised by this research effort will help increase the relevance and influence of marketing as a discipline in the future. In doing so, we certainly do not need to abandon the lessons of the past. Rather, we must leverage the marketing discipline's strength in conducting systematic empirical work. 


\section{REFERENCES}

Arthur, Brian (1994), Increasing Returns and Path Dependence in the Economy. Ann Arbor, MI: University of Michigan Press.

Bollier, David (1998), The Global Advance of Electronic Commerce. Washington, DC: The Aspen Institute.

Brynjolfsson, Erik and Chris F. Kemerer (1995), "Network Externalities in Microcomputer Software: An Econometric Analysis of the Spreadsheet Market," working paper, MIT Center for Information Systems Research, No. 265.

Capon, Noel and Rashi Glazer (1987), "Marketing and Technology: A Strategic Coalignment," Journal of Marketing, 51 (July), $1-14$.

Dyson, Esther (1995), "Intellectual Value," Wired, (accessed August 3), [available at http://www.wired.com/wired/archive/3.07/ dyson.html].

Farrell, Joseph, Hunter K. Monroe, and Garth Saloner (1998), "The Vertical Organization of Industry: Systems Competition Versus Component Competition," Journal of Economics and Management Strategy," 7 (Summer), 143-82.

—_ and Garth Saloner (1985), "Standardization, Compatibility, and Innovation," RAND Journal of Economics, 16, 70-83.

Fishburn, Peter, Andrew M. Odlyzko, and Ryan C. Siders (1997), "Fixed Fee Versus Unit Pricing for Information Goods: Competition, Equilibria and Price Wars," (accessed August 2), [available at http://www.firstmonday.dk/issues/issue2-7/ odlyzko/index.html].

Glazer, Rashi (1991), "Marketing in an Information-Intensive Environment: Strategic Implications of Knowledge as an Asset," Journal of Marketing, 55 (October), 1-19.

Grenadier, S. and A.M. Weiss (1997), "Investments in Technological Innovations: An Options Pricing Approach," Journal of Financial Economics, 44, 397-416.

Iansiti, Marco and Jonathan West (1997), "Technology Integration: Turning Great Research into Great Products," Harvard Business Review, 76 (May/June), 69-79.

Jaffe, Adam B. (1986), "Technological Opportunity and Spillovers of R\&D: Evidence from Firm's Patents Profits and Market Value," American Economic Review, 76 (December), 984-1001.

- (1989), "Real Effects of Academic Research," American Economic Review, 79 (5), 957-70.

Kaysen, Carl (1956), United States v. United Shoe Machinery Corporation: An Economic Analysis of an Antitrust Case. Cambridge, MA: Harvard University Press.

Liebowitz, Stephen J. and Stephen Margolis (1990), "The Fable of the Keys," Journal of Law and Economics, 33 (April), 1-26. and (1995), "Path Dependence, Lock-In and History," Journal of Law, Economics and Organization, 11 (April), 205-26.

Mandel, Michael (1998), “Innovation You Ain't Seen Nothing Yet," BusinessWeek, (August 31), 60-63

Mokyr, Joel (1990), The Lever of Riches. New York: The Free Press.

Morris, Charles R. and Charles H. Ferguson (1993), "How Architecture Wins Technology Wars," Harvard Business Review, 72 (March/April), 86-95.

Norton, John A. and Frank M. Bass (1987), "Diffusion Theory Model of Adoption and Substitution for Successive Generations of Technology Intensive Products," Management Science, 33 (September), 1069-86.
Passer, Harold (1953), The Electrical Manufacturers, 1875-1900. Cambridge, MA: Harvard University Press.

Polanyi, Michael (1962), Personal Knowledge: Towards a PostCritical Philosophy. New York: Harper and Row.

Porter, Michael E. (1985), Competitive Strategy: Creating and Sus. taining Superior Performance. New York: The Free Press.

Quinn, James Brian (1992), Intelligent Enterprise. New York: The Free Press.

- Jordan J. Baruch, and Karen Anne Zien (1997), Innovation Explosion. New York: The Free Press.

Reddy, Mohan (1987), "Technology, Standards, and Markets; A Market Institutionalization Perspective," in Product Standardization and Competitive Strategy, H. Landis Gabel, ed. Holland: Elsevier Science Publishers B.V., 135-37.

Romer, Paul M. (1990), "Endogenous Technological Change," Journal of Political Economy, 98 (5), S71-90.

Rosenberg, N. (1976), "On Technological Expectations," Economic Journal, 86, 523-35.

Sanchez, Ron and Joseph T. Mahoney (1996), "Modularity, Flexibility and Knowledge Management in Product and Organization Design," Strategic Management Journal, 17 (Winter Special Issue), 63-76.

Shanklin, William L. and John K. Ryans Jr. (1984), Marketing High Technology. Lexington, MA: D.C. Heath.

Shapiro, Carl (1996), "Antitrust in Network Industries," speech delivered to American Law Institute and American Bar Association, San Francisco, CA (January 25), [available at http:// usdoj.gov/atr/public/speeches/shapir.mar].

Technology in the National Interest (1996), Committee on Civilian Industrial Technology, Technology Administration, U.S. Department of Commerce, (accessed July 17, 1998) [available at http://www.ta.doc.gov/reports/TechNI/TNI.pdf].

Teece, David J. (1988), “Capturing Value from Technological Innovation: Integration, Strategic Partnering, and Licensing Decisions," Interfaces, 18 (3), 46-61.

Thurow, Lester C. (1997), "Needed: A New System of Intellectual Property Rights," Harvard Business Review, 76 (September/ October), 95-103.

Varian, Hal R. (1996) "Buying, Renting and Sharing Information Goods," working paper, Economics Department, University of California, Berkeley.

(1997), "Versioning Information Goods," working paper, Economics Department, University of California, Berkeley.

von Hippel, Eric (1986), "Lead Users: A Source of Novel Product Concepts," Management Science, 32 (7), 791-805.

Weiss, A.M. (1994), "The Effects of Expectations on Technology Adoption: Some Empirical Evidence," Journal of Industrial Economics, 42 (December), 1-19.

- and J. Heide (1993), "The Nature of Organizational Search in High-Technology Markets," Journal of Marketing Research, 30 (May), 220-33.

Wilson, Lynn O., Allen M. Weiss, and George John (1990), "Unbundling of Industrial Systems," Journal of Marketing Research, 27 (May), 123-38.

Workman, John P., Jr. (1993), "Marketing's Limited Role in New Product Development in One Computer Systems Firm," Jour. nal of Marketing Research, 30 (November), 405-21. 
Copyright of Journal of Marketing is the property of American Marketing Association and its content may not be copied or emailed to multiple sites or posted to a listserv without the copyright holder's express written permission. However, users may print, download, or email articles for individual use. 